\title{
ÖGUM-Mitteilungen
}

Österreichische Gesellschaft fïr Ultraschall

in der Medizin

\section{Ultraschall 2021}

Liebe Freundinnen und Freunde des Ultraschall-Dreiländertreffens,

nach der durch die COVID-19-Pandemie bedingten Absage der Präsenzveranstaltung in Wien freut es uns nun umso mehr, Ihnen ein „Best of“ des geplanten Programms online anbieten zu können. Von Mittwoch, 27.10.2021, bis Sonntag, 31.10.2021, bieten wir Ihnen ein buntes Programm mit didaktischen Vorträgen zu einem großen Spektrum an relevanten und spannenden Themen an.

Der Mittwoch, 27.10.2021, ist ganz der Pränataldiagnostik gewidmet, der Donnerstag, 28.10.2021, dem Abdomen und Retroperitoneum und der Freitag, 29.10.2021, der Echokardiografie, der Notfallsonografie und dem Thorax-Ultraschall. Der Samstag, 30.10.2021, und der Sonntag, 31.10.2021, konzentrieren sich schließlich auf den Nervenultraschall, den muskuloskelettalen Ultraschall, den urologischen Ultraschall und den Kopf-Hals-Ultraschall.

Wir sind davon überzeugt, dass sich in diesem Programm für alle Mitglieder der 3 Ultraschallgesellschaften und alle ultraschallinteressierten Teilnehmerinnen und Teilnehmern attraktive und informative Themen finden. Die Teilnahmegebühren

\section{Ultraschall 2021

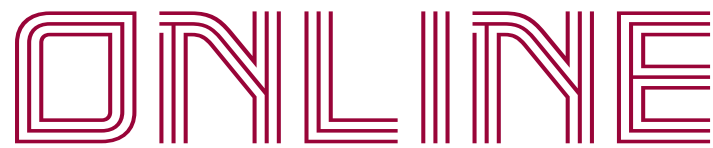 25.-31. OKTOBER 2021}

von 110,- $€$ für eine Tageskarte und 290,- $€$ für Mitglieder für den gesamten Online-Kongress sind im Vergleich zu anderen Kongressen sehr günstig gehalten.

Um auch unseren jungen Wissenschaftlern eine Plattform zu bieten, findet am 24.10.2021 der Dreiländertreffen-,,Science Day“ statt. Neben spannenden Vorträgen von renommierten Experten zum Thema „Wie schreibe ich eine wissenschaftliche Arbeit?" haben hier die Autoren der angenommenen Abstracts die Möglichkeit, ihre Arbeiten zu präsentieren und zu diskutieren. Die Teilnahme am Science Day ist kostenfrei.

Wir möchten uns auf diesem Wege bei allen Kolleginnen und Kollegen bedanken, die sich bereit erklärt haben, ihren Vortrag online zu halten, und freuen uns schon auf einen spannenden Kongress.

Helmut Prosch

Kongresspräsident

Barbara Pertl

ÖGUM Präsidentin

Hannes Gruber

ÖGUM Sekretär

im Namen des Vorstandes

Alle Details finden Sie auf der Kongresswebsite: www.ultraschall2021.at. 